\title{
Drug-eluting stents: A study of international practice
}

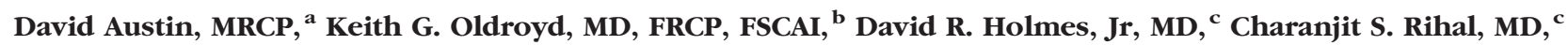
P. Diane Galbraith, BN, MSc, ${ }^{\mathrm{d}}$ William A. Ghali, MD, MPH, ${ }^{\mathrm{d}}$ Victor Legrand, MD, PhD, ${ }^{\mathrm{e}}$ Yves Taeymans, MD, PhD, ${ }^{\mathrm{f}}$ Alex McConnachie, PhD, ${ }^{\mathrm{g}}$ and Jill P. Pell, MD, FESC, ${ }^{\mathrm{a}}$ on behalf of the APPROACH Investigators, Belgian Working Group on Invasive Cardiology, Mayo Clinic PCI Registry, and Scottish Coronary Revascularisation Registry Glasgow, United Kingdom; Rochester, MN; Calgary, Canada; and Liege, and Gent, Belgium

Objective We aimed to analyze trends in drug-eluting stents (DES) use in four international health care and regulatory settings.

Background Accounts suggest a differential approach to DES internationally and recent reductions in use following reports of late stent thrombosis. Current studies of clinical practice are limited in their scope.

Methods Data were pooled from angioplasty registries in Alberta (Canada), Belgium, Mayo Clinic (Rochester, MN), and Scotland (UK) that have routinely recorded consecutive patients treated since 2003. Trend analysis was performed to examine variations in DES use over time and by clinical subgroup.

Results A total of 178,504 lesions treated between January 2003 and September 2007 were included. In the Mayo Clinic Registry, rapid adoption to a peak of $91 \%$ DES use for all lesions by late 2004 was observed. In contrast, Alberta and Scotland showed delayed adoption with lower peak DES use, respectively, $56 \%$ and $58 \%$ of lesions by early 2006 . Adoption of DES in Belgium was more gradual and peak use of $35 \%$ lower than other registries. Reductions in DES use were seen in all data sets during 2006, although this varied in absolute and relative terms and by clinical subgroup.

Conclusion Adoption and use of DES showed wide variation in four countries. The determinants of use are complex, and it is likely that nonclinical factors predominate. Recent reductions in use may be as a consequence of publicity and concerns regarding late stent thrombosis. The optimum application of DES in clinical practice is unclear and is reflected in the degree of international variation demonstrated. (Am Heart J 2009;158:576-84.)

Drug-eluting stents (DES) are proven to reduce restenosis in selected populations compared with bare metal stents (BMS). ${ }^{1-4}$ Consequently, they were licensed for use across Europe and North America. Despite their established effectiveness in randomized controlled trials, the clinical and cost effectiveness of unrestricted DES use in routine practice has since been debated. ${ }^{5-8}$ Given the financial consequences of widespread use of these more expensive stents, some health care systems introduced guidelines or encouraged restricted indications for DES use; such approaches have varied. ${ }^{9-12}$

From the ${ }^{a}$ Department of Public Health and Health Policy, University of Glasgow, Glasgow, United Kingdom, 'bepartment of Cardiology, Western Infirmary, Glasgow, United Kingdom, 'Division of Cardiovascular Diseases, Mayo Clinic, Rochester, MN, 'University of Calgary, Calgary, Canada, ${ }^{e} \mathrm{CHU}$ de Liege, Liege, Belgium, 'University Hospital Gent, Gent, Belgium, and ${ }^{9}$ Robertson Centre for Biostatistics, University of Glasgow, United Kingdom.

Submitted January 12, 2009; accepted July 14, 2009.

Reprint requests: Jill Pell, MD, FESC, Department of Public Health and Health Policy, University of Glasgow, 1 Lilybank Gardens, G12 8RZ Glasgow, UK.

E-mail: j.pell@clinmed.gla.ac.uk

0002-8703/\$ - see front matter

(C) 2009, Mosby, Inc. All rights reserved.

doi:10.1016/i.ahi.2009.07.033
Against this background, abstracts presented at the World Congress of Cardiology (WCC) in September 2006 brought into question the safety of DES and, in particular, the complication of late stent thrombosis. ${ }^{13-17}$ Anecdotal accounts suggest a differential approach to DES use internationally and reductions in use following the issue of late stent thrombosis. Previous studies have examined the uptake of DES within single health care systems or analyzed the impact of DES on patient selection for percutaneous coronary intervention ( $\mathrm{PCI}$ ) versus coronary artery bypass grafting. ${ }^{18-20}$ However, there are limited patient-level analyses of international practice. This study aimed to show whether the adoption and use of DES varied internationally, and how the stent thrombosis controversy has affected practice.

\section{Methods}

Data sources and patient populations

This study involved collaboration between centers from four countries that have established large regional or national PCI data sets of consecutive patients treated in routine clinical practice. The data sets included were the APPROACH Registry (Alberta, 
Table I. Characteristics of registry data sets

\begin{tabular}{|c|c|c|c|c|c|c|}
\hline Registry & Location & $\begin{array}{c}\text { Year } \\
\text { established }\end{array}$ & $\begin{array}{c}\text { PCI } \\
\text { centers }\end{array}$ & $\begin{array}{l}\text { Catchment } \\
\text { population }\end{array}$ & Data collection & DES licensing \\
\hline APPROACH & Alberta, Canada & 1995 & 3 & 3.5 million & All patients, prospective & $\begin{array}{l}\text { SES: November } 2002 \\
\text { PES: September } 2003\end{array}$ \\
\hline BWGIC & Belgium & 2003 & 32 & 10.4 million & All patients, prospective & $\begin{array}{l}\text { SES: April } 2002 \\
\text { PES: January } 2003\end{array}$ \\
\hline Mayo Clinic PCl & Rochester, MN & 1978 & 1 & 0.5 million & All patients, prospective & $\begin{array}{l}\text { SES: April } 2003 \\
\text { PES: March } 2004\end{array}$ \\
\hline $\begin{array}{l}\text { Scottish Coronary } \\
\quad \text { Revascularisation Registry }\end{array}$ & Scotland, UK & 1997 & 7 & 5.1 million & All patients, prospective & $\begin{array}{l}\text { SES: April } 2002 \\
\text { PES: January } 2003\end{array}$ \\
\hline
\end{tabular}

Canada), BWGIC Registry, Mayo Clinic PCI Registry (Rochester, $\mathrm{MN}$ ), and the Scottish Coronary Revascularisation Registry (Scotland, UK) (Table I). In each registry, data collection and entry is prospective and performed by a combination of administrative and clinical staff. All data were stripped of unique patient identifiers. Data extracts were obtained from the APPROACH registry, Mayo Clinic PCI registry, and Scottish Revascularisation Registry for all consecutive patients undergoing successful PCI from January 2003 to September 2007 inclusive. Belgian data were available from November 2003 to September 2007. Changes in the collection method for the Belgian registry (introduced in October 2005) resulted in those data only being used for some of the study analyses.

\section{Variables and definitions}

Data fields obtained included patient-level demographic details, diabetic status, indication for PCI, and lesion-level angiographic details including type of intervention, type of stent, treated vessel, and stent dimensions. Diabetes mellitus was defined as either type 1 or type 2 diabetes mellitus treated with insulin or oral hypoglycemic agents. Clinical presentation was recorded as the principal indication for PCI. Stent diameter was the maximum diameter stent successfully deployed within each lesion, and lesion length was the total length stented.

\section{Statistical analysis}

The unit of analysis was the lesion. We defined the binary outcome for each lesion as treatment with either DES or BMS. Patients who did not receive a stent were excluded from the analysis. Case mix at baseline was summarized for each registry. Patient and lesion level variables are presented in relation to their respective denominators. Variables are reported as number (percentage) for categorical data, mean (SD) for normally distributed data, and median (interquartile range) for skewed data. Data were compared between countries using one-way analysis of variance (normal distribution), Kruskall-Wallis test (skewed or ordinal data) or $\chi^{2}$ test (categorical data). The date of each procedure was recorded to the level of calendar month. The overall percentage of patients treated with a DES was calculated by country or region over the period of overlap between the US, Canadian, and Scottish registries (January 2003September 2007). Corresponding data from the Belgian registry were available since November 2003 for overall analysis and October 2005 for diabetic and clinical indication sub-groups.

To present the data, local likelihood-based, nonparametric logistic regression estimates ${ }^{21}$ of the trends in percentage DES use were calculated by country and shown graphically with $95 \%$ CIs. The SD of the normal kernel function used was chosen to be 4 months (120 days), based on a visual inspection of figures using a range of alternative parameters. First, an overall unadjusted time trend by country model was constructed. Figures were then produced in a similar fashion for subsets of data: vessel dimensions $(\geq 3 /<18, \geq 3 / \geq 18,<3 /<18$ and $<3 / \geq 18$ $\mathrm{mm}$ ), diabetes, and ST-elevation myocardial infarction (STEMI). Finally, to assess the possible effect of case mix differences between countries, a Generalized Additive Regression model was used to estimate the time trends in DES use by country. This model was adjusted for age, sex, clinical presentation, diabetic status, vessel diameter and lesion length. Smoothing analyses were performed using the "sm" package (v2.1) within R for Windows v2.7.0, ${ }^{22}$ and the adjusted model constructed using the "mgcv" package (v1.3-30), with the nonlinear time trend modeled using cubic splines. No extramural funding was used to support this work. The authors are solely responsible for the design and conduct of this study, all study analyses, the drafting and editing of the manuscript, and its final contents

\section{Results}

\section{Baseline characteristics}

All consecutive lesions treated with a stent during the study period were included in the overall analysis. In total, 178,504 stented lesions in the four geographical areas were included in the overall comparison. For the analyses by diabetic and clinical indication subgroup, 118,827 lesions were included from the four registries. For analyses by lesion dimension and the adjusted model, 68,781 lesions were included from the APPROACH, Mayo Clinic, and Scottish registries. Procedural volume during the study was constant within the APPROACH, Mayo Clinic, and BWGIC Registries but was seen to increase year-on-year in the Scottish Registry. Case mix for each registry period is described in Table II. Statistical differences between registries were identified for clinical and demographic case mix variables.

\section{Adoption and peak use of drug-eluting stents}

The Mayo Clinic PCI Registry demonstrated rapid adoption of DES into clinical practice (Figures 1-5). Peak use was observed by February 2005 when $91 \%$ of stented lesions were treated with a DES. Peak use of $>89 \%$ 
Table II. Characteristics of patients and lesions within each registry

\begin{tabular}{|c|c|c|c|c|c|}
\hline & $\begin{array}{c}\text { Approach } \\
\text { Registry* (Canada) }^{*}\end{array}$ & $\begin{array}{c}\text { Mayo Clinic } \\
\text { Registry }^{*} \text { (USA) }\end{array}$ & $\begin{array}{c}\text { Scottish } \\
\text { Registry* }^{\star} \text { (UK) }\end{array}$ & $\begin{array}{l}\text { BWGIC Registry }^{\dagger} \\
\text { (Belgium) }\end{array}$ & $\boldsymbol{P}$ \\
\hline Patients & 19515 & 6955 & 23507 & 43759 & \\
\hline Age (mean $\pm S D)$ & $62.7(11.7)$ & $66.5(12.3)$ & $61.6(10.9)$ & $67.3(12.5)$ & $<.001$ \\
\hline Male & $14942(76.4)$ & $4903(70.5)$ & $16630(70.7)$ & $31682(72.4)$ & $<.001$ \\
\hline Diabetes mellitus & $4405(23.1)$ & $1712(24.8)$ & 3100 (14.1) & 8621 (19.7) & $<.001$ \\
\hline Indication for $\mathrm{PCl}$ & & & & & $<.001$ \\
\hline $\begin{array}{l}\text { Stable or } \\
\text { unstable angina }\end{array}$ & $8574(45.7)$ & $3582(66.4)$ & 15444 (67.7) & 29669 (67.8) & \\
\hline Non-STEMI & $3849(20.5)$ & $679(12.6)$ & $4838(21.2)$ & $4901(11.2)$ & \\
\hline STEMI & $6322(33.7)$ & $1131(21.0)$ & $2535(11.1)$ & $9146(20.9)$ & \\
\hline $\begin{array}{l}\text { Number of vessels } \\
\text { treated/procedure }\end{array}$ & & & & & $<.001$ \\
\hline Single vessel & 17845 (87.0) & $6013(86.5)$ & 18877 (83.0) & 40433 (92.4) & \\
\hline 2 Vessels & $2318(11.4)$ & $861(12.4)$ & $3543(15.6)$ & $3150(7.2)$ & \\
\hline 3 Vessels & $171(0.8)$ & $81(1.1)$ & $317(1.4)$ & $176(0.4)$ & \\
\hline \multicolumn{6}{|l|}{ Lesions } \\
\hline Total & 27732 & 9266 & 31783 & 50046 & \\
\hline 2003 & 5076 & 1941 & 5209 & - & \\
\hline 2004 & 6153 & 2078 & 6154 & - & \\
\hline 2005 & 6445 & 2010 & 7173 & - & \\
\hline 2006 & 5867 & 2034 & 7451 & 29069 & \\
\hline $2007^{*}$ & 4191 & 1203 & 5796 & 20977 & \\
\hline \multicolumn{6}{|l|}{ Treated vessel } \\
\hline RCA & 10557 (38.2) & 2949 (31.8) & 11273 (35.5) & - & $<.001$ \\
\hline LCx & $6099(22.1)$ & 2047 (22.1) & 7060 (22.2) & - & \\
\hline LAD & 10039 (36.3) & 3417 (36.9) & 12017 (37.8) & - & \\
\hline LMCA & $94(0.3)$ & $188(2.0)$ & $436(1.4)$ & - & \\
\hline Bypass graft & 538 (1.9) & 665 (7.2) & 991 (3.1) & - & \\
\hline \multicolumn{6}{|l|}{ Stented length $(\mathrm{mm})$} \\
\hline median (IQR) & $18(15-24)$ & $18(13-23)$ & $18(15-27)$ & - & $<.001$ \\
\hline$<16 \mathrm{~mm}$ & $8588(31.2)$ & $3101(34.6)$ & $9215(29.0)$ & - & $<.001$ \\
\hline $16-30 \mathrm{~mm}$ & $14601(53.1)$ & $4629(51.7)$ & 15681 (49.3) & - & \\
\hline$\geq 30 \mathrm{~mm}$ & 4305 (15.7) & 1223 (13.7) & $5035(15.8)$ & - & \\
\hline Stent diameter (mm) & & & & - & \\
\hline Median (IQR) & $3.0(2.5-3.5)$ & $3.0(3.0-3.5)$ & $3.0(2.75-3.5)$ & - & $<.001$ \\
\hline$<3 \mathrm{~mm}$ & $9651(35.1)$ & $1881(21.0)$ & $8384(26.4)$ & - & $<.001$ \\
\hline$\geq 3 \mathrm{~mm}$ & 17838 (64.9) & $7062(79.0)$ & $21568(67.9)$ & - & \\
\hline
\end{tabular}

Probability statistics are derived from 1-way analysis of variance (normal distribution), Kruskall-Wallis test (skewed or ordinal data), or $\chi^{2}$ test (categorical data). $R C A$, Right coronary artery; $L C x$, left circumflex artery; $L A D$, left anterior descending artery; $L M C A$, left main coronary artery; $I Q R$, interquartile range.

* January 2003 to September 2007.

†From January 2006 to Sept 2007

was observed in all sub-groups (Figures 2-4). In Alberta, the unadjusted estimates demonstrated a more gradual uptake of DES with peak use observed in January 2006 at $56 \%$ of lesions (Figure 1). In contrast to Alberta, DES uptake in Scotland exhibited a prolonged phase of relatively low utilization before a steeper adoption curve during 2005. DES use within Scotland peaked at $58 \%$ of lesions in March 2006 (Figure 1). At peak use, after adjustment for case mix, there was no statistical difference between the UK and Canadian registries (Figure 5). The lowest and latest peak adoption was within Belgium, where DES use peaked at $35 \%$ of stented lesions in June 2006 (Figure 1).

\section{Patient selection for drug-eluting stents}

In Alberta and Scotland, selection for DES on patient and lesion characteristics was evident throughout. At peak adoption, high levels of DES use in lesions at highest baseline risk of restenosis $(<3 / \geq 18 \mathrm{~mm})$ was observed: $75 \%$ in Alberta, $87 \%$ in Scotland and $98 \%$ at the Mayo Clinic (Figure 2, D). However, variation between registries was greater in lesions at moderate risk of restenosis $(>3 / \geq 18, \leq 3 /<18 \mathrm{~mm}$ [Figure $2, B$ and $C$ ]) and further still for lesions at lowest baseline risk $(>3 /<18 \mathrm{~mm}$ [Figure 2, A]) due to lower use in Alberta and Scotland among these subgroups. In Alberta and Scotland, relatively higher DES use by subgroup was also observed for diabetic patients (Figure 3). In contrast, lower DES use was observed for STEMI (Figure 4) in Scotland and Alberta, but not the Mayo Clinic.

Where Belgian subgroup data were available, they demonstrated marked differences in use by diabetic status. DES use among people with diabetes showed no statistical difference to the Mayo Clinic registry in late 
Figure 1

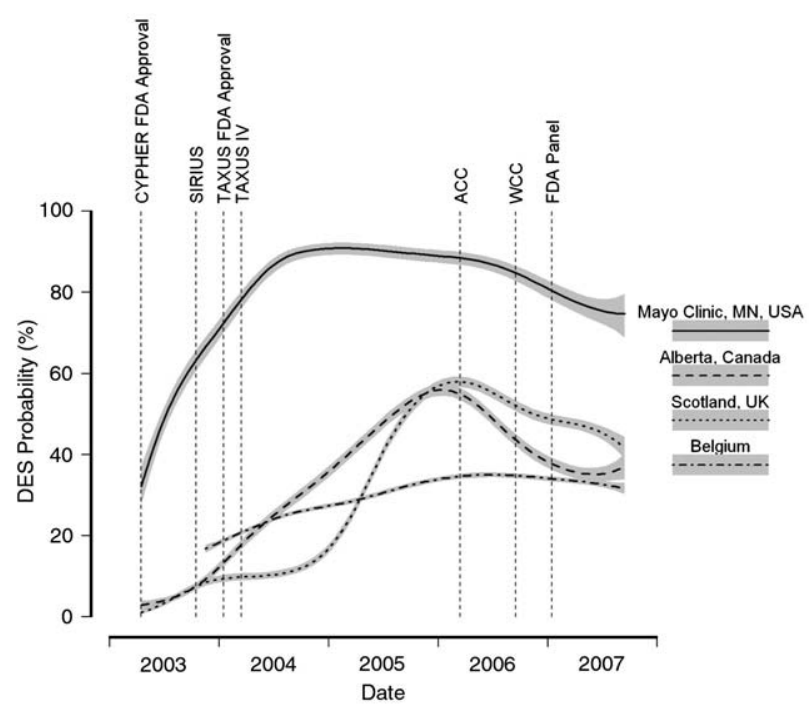

Crude DES use by registry (smooth estimate with 95\% Cl).

2006 and was higher than both the Scottish and Canadian registries (Figure 3). In common with the Scottish and Canadian registries, relatively lower DES use was observed for STEMI (Figure 4).

\section{Reductions in drug-eluting stent use}

The Mayo Clinic PCI Registry recorded small reductions in DES use during 2005, followed by a steeper decline during 2006. From the unadjusted smoothed trend line, the estimated absolute reduction from peak DES use was $16 \%$, a relative reduction of $18 \%$. In comparison with the other registries, DES use remained statistically higher throughout maintained $>74 \%$ of stented lesions (Figures 1 and 5). Differential reductions in DES use by clinical indication were observed in the US registry. Reductions in DES use were greater in patients treated for STEMI (Figure 4), and $>3 /<18-\mathrm{mm}$ lesions (Figure 2).

In both Alberta and Scotland, DES use started to decline in the second quarter of 2006 (Figures 1 and 5). For Alberta, a 19\% absolute reduction and 34\% relative reduction from peak DES use was observed by the end of the study period. In Scotland, a smaller absolute reduction of $16 \%$, a relative reduction of $28 \%$, was observed. In both registries, pre-evident patient selection remained apparent. In contrast, the BWGIC Registry showed a $1 \%$ absolute and $3 \%$ relative reduction in DES use during 2006 (Figure 1). By the end of the study period, DES were used in $75 \%$ of stented lesions in the Mayo Clinic, $42 \%$ in Scotland, 37\% in Alberta and 32\% in Belgium (Figure 1).

\section{Discussion}

This study of PCI practice in four countries demonstrated wide variations in the adoption and utilization of DES. We also established that DES use reduced in all registries during 2006 and 2007; the timing and extent of these reductions varied by registry. Marked differences in use by clinical subgroup were evident throughout and observations held even after adjustment for case mix differences.

\section{Adoption and peak use}

Variations in adoption and peak use exist despite the international nature of clinical scientific evidence and the widespread marketing and availability of DES. In the Mayo Clinic Registry, increased DES use corresponded closely with the Food and Drug Administration approval of the sirolimus-eluting Cypher stent ${ }^{23}$ (SES, April 2003) and then paclitaxel-eluting Taxus stent ${ }^{24}$ (PES, March 2004) and mirror previous descriptions of US adoption patterns. ${ }^{18}$ Both across Europe and in Canada, prior licensing of SES (CE Mark April 2002, Health Canada approval November 2002) and PES (CE Mark, January 2003, Health Canada approval September 2003) had occurred. Therefore, the delayed adoption of DES outside the United States was not related to delayed regulatory approval in these countries.

Drug-eluting stent use varies at hospital level within single health care systems. ${ }^{18-20}$ Influences are thought to include differences in funding (eg, private/government, proportion of patients insured), type of hospital (eg, academic/non academic, urban/rural), and local priority setting. Individual interventional cardiologists also vary in their use of DES, and their rate of technology adoption. ${ }^{19,25}$ Furthermore, it is possible that, in the United States in particular, adoption may have been partly driven by concerns of medical malpractice with underuse. ${ }^{26}$ However, such disparities in international adoption patterns seem unlikely to be fully explained by individual clinician preference, local hospital factors, differing patient selection for PCI over other treatments (such as coronary artery bypass grafting or medical therapy), or unaccounted for clinical factors.

Indeed, the adoption of high cost new technologies are thought to be sensitive to the stringency of regulation, the responsiveness of payment systems to changes in practice (eg, centrally funded, reimbursement, private), the autonomy of local decision making, and overall levels of health care funding. ${ }^{27}$ In this study, we showed rapid uptake of DES at the Mayo Clinic-a private, not-forprofit, academic institution within the influence of the US health care system, where stent choice was at the discretion of individual operators. As an example here, there is low regulation, a payment system rapidly responsive to changes in practice, high local autonomy, 


\section{Figure 2}
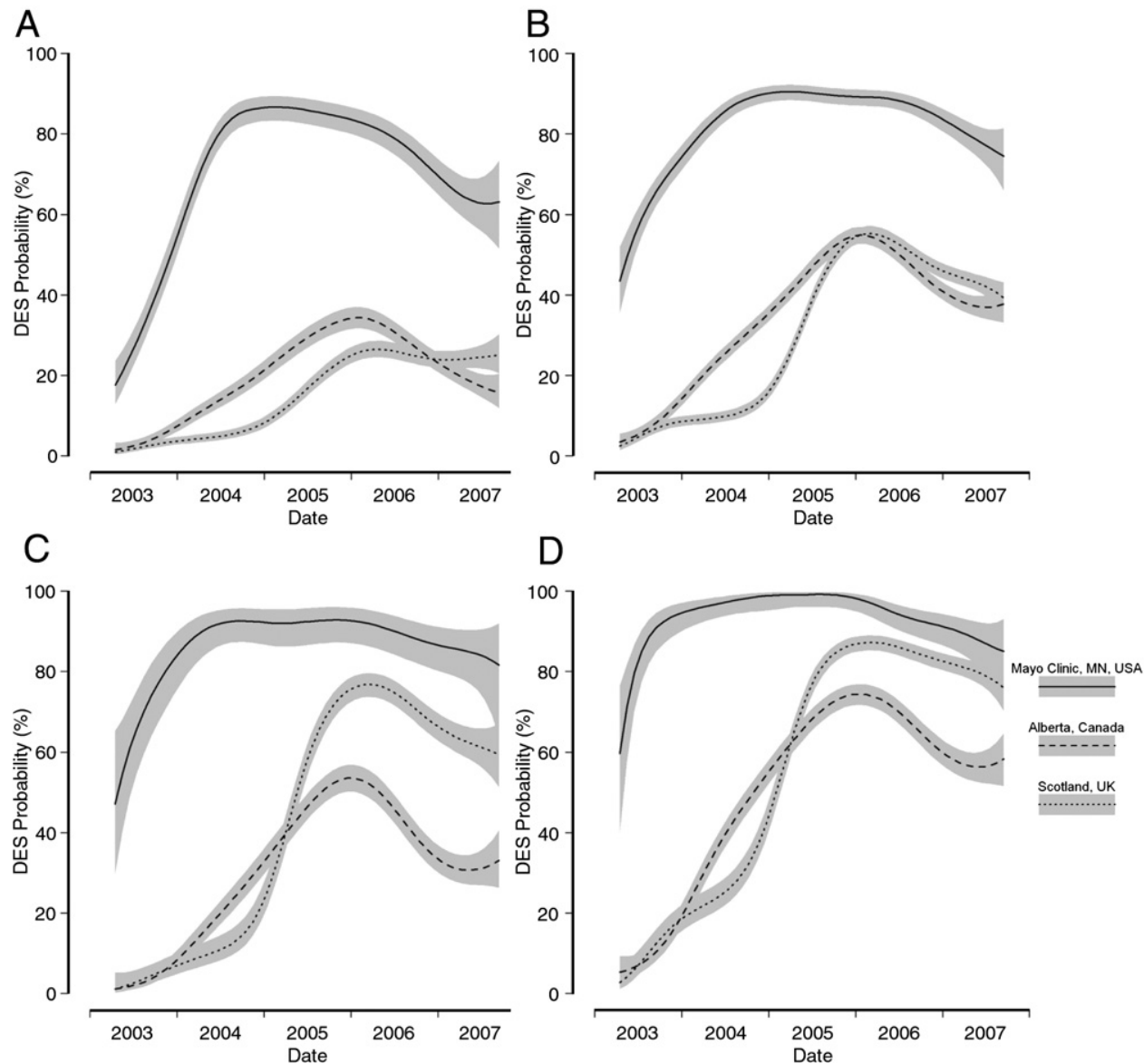

Drug-eluting stent use by registry for lesion dimensions: $\geq 3 /<18(\mathbf{A}), \geq 3 / \geq 18(\mathbf{B}),<3 /<18(\mathbf{C})$, and $<3 / \geq 18 \mathrm{~mm}$ (D) (smooth estimate with $95 \% \mathrm{Cl}$ ).

and high levels of health care funding. Such an environment encourages rapid and high levels of technology adoption as seen with DES in this study.

As a further illustration, early policy in Belgium was to only reimburse the full cost of DES to hospitals for use in diabetic patients. ${ }^{12}$ The influence of this policy on practice is clearly demonstrated in this study. In this case, regulation and payment were strictly controlled, local autonomy was therefore low, and overall costs were controlled; the result was slow adoption and low peak use. A recent health technology assessment in Belgium has concluded against the extension of DES use in other clinical indications on cost grounds. ${ }^{12}$

\section{Differential selection for drug-eluting stents}

We demonstrated differential selection for DES in Scotland and Alberta based on patient and lesion characteristics. In the United Kingdom and Canada, early cost-effectiveness analyses and health technology assessments resulted in clinical policies that favored the "targeting" of DES to patients felt to be at higher risk of restenosis. ${ }^{6,9,11,28-30}$ In both the United Kingdom and Canada, these recommendations explicitly considered cost and were designed to limit overall use. In the United Kingdom, The National Institute for Health and Clinical Excellence recommended DES in non-myocardial infarction patients with lesions $>15$ $\mathrm{mm}$ length and in vessels $<3 \mathrm{~mm} .^{9,10}$ Using similar rationale, the Canadian province of Ontario recommended DES use in diabetic patients, lesions $>18 \mathrm{~mm}$, vessels of $\leq 2.75 \mathrm{~mm}$, or an otherwise defined high risk lesion. ${ }^{11}$

Both UK and Canadian health care systems are largely publicly funded, although neither employs a system of direct reimbursement for DES used in recommended indications. In such health care systems, the interventional cardiologist plays a role in "gate-keeping" to ensure overall costs are limited and DES are used for those considered to have the greatest clinical "need." Our data demonstrate that such policy has influenced clinical practice during the period of study. 


\section{Figure 3}

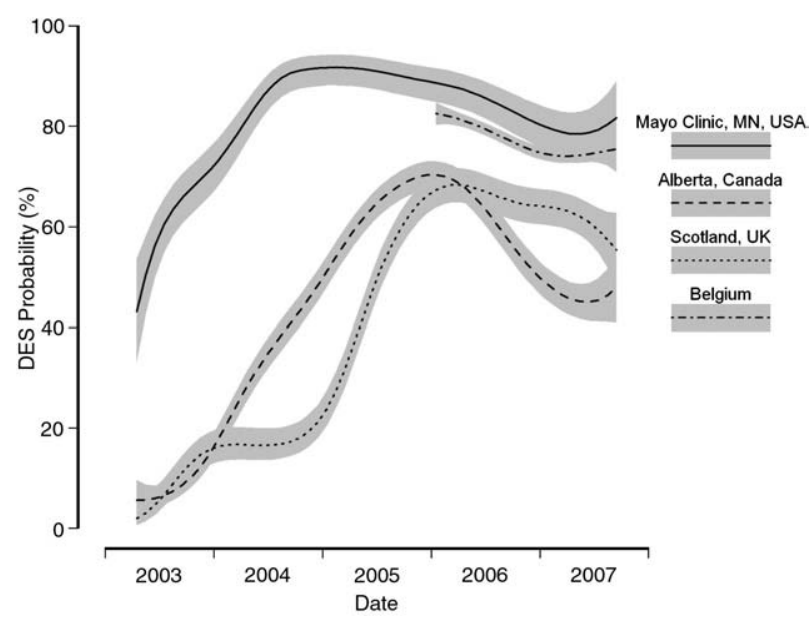

Drug-eluting stent use by registry for diabetics (smooth estimate with $95 \% \mathrm{Cl})$.

\section{Figure 4}

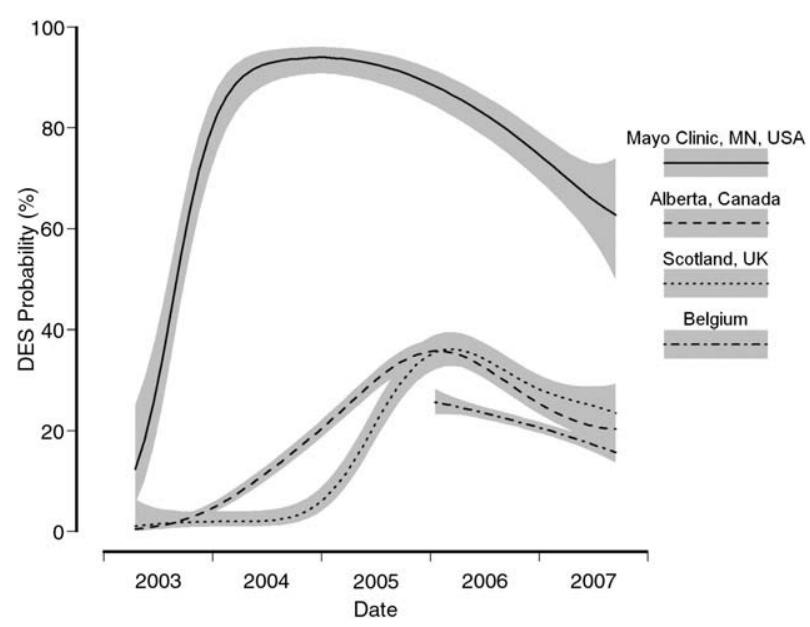

Drug-eluting stent use by registry for STEMI (smooth estimate with $95 \% \mathrm{Cl})$.

\section{Reductions in drug-eluting stent use}

Several studies, initially presented at the WCC conference in September 2006, questioned the safety of DES linked to the risk of late stent thrombosis. ${ }^{13-17}$ Subsequent published meta-analyses and large observational studies have since shown safety and efficacy of DES without major safety concerns. ${ }^{31-36}$ This evidence is particularly strong for "on-label" patients studied in the pivotal randomized controlled trials, although further studies have included other important subgroups. ${ }^{37-40}$ It is likely, however, that the controversy
Figure 5

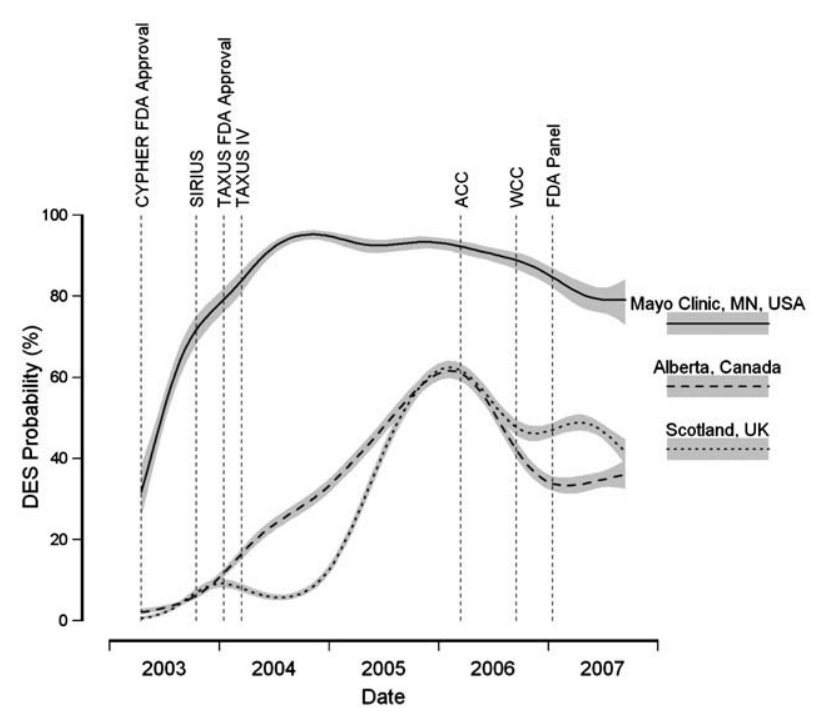

Adjusted DES use by registry (smooth estimate with 95\% CI).

and the resultant adverse publicity have influenced clinical decisions with all registries demonstrating lower DES use during 2007 following declining use during 2006. Although the WCC conference in September 2006 is seen as an important landmark, our data suggest reducing DES use commenced prior to this time point. Thus, the "turn point" for reductions in DES use is perhaps surprising. A possible explanation is that physicians were beginning to manage individual cases of late stent thrombosis in clinical practice; a complication described as far back as $2004 .^{41,42}$ Increasing caution in the use of DES, before the adverse publicity in September 2006, may have resulted.

By 2007, evidence of selection of patients for DES was evident within the US-based registry, in particular, reduced use among patients treated for STEMI. In the Canadian and UK-based registries, pre-evident factors effecting selection remained, and in common with the Mayo Clinic Registry, reductions in patients treated for STEMI were particularly marked. A possible explanation lies in the importance of dual antiplatelet therapy in preventing thrombotic events ${ }^{43,44}$; an assessment of future patient compliance is particularly challenging within the acute setting and may discourage the use of DES.

Implications and determinants of use

The optimum strategy for adoption and use for DES is not clear. Were DES adopted too early, particularly within United States, before a full evaluation of the device in many clinical scenarios? Targeted DES use, for example, in the United Kingdom and Canada, may make economic sense. However, "off-label" use was encouraged (eg, very 
long lesions), and many patients for whom benefit and safety was established were excluded from guidance. Furthermore, equity of use in systems where the interventional cardiologist acts as "gatekeeper" can be compromised. ${ }^{19}$ Finally, a strict reimbursement system, such as in Belgium, appears affective in controlling uptake, limiting overall use and is probably more equitable. However, this system may be less flexible to change with the emergence of new data.

Clinically efficacious but expensive new technologies are frequently developed for use in clinical practice. Drug-eluting stents are a classic case in point. We have shown wide international differences in the approach to DES and varying reductions in use following reports of late stent thrombosis. These findings raise generic questions with respect to the determinants of utilization which include clinical evidence and its applicability to actual practice; public and medical perception, including the importance of marketing and (adverse) publicity; the role of national regulatory and rationing agencies; and the influence and extent of health service control.

\section{Strengths and weaknesses of the study}

Our study has provided an overview of international PCI practice since the introduction of DES. While international differences in DES use and recent reductions are often alluded to, no study to date has outlined this in detail. The comparison of a sample of North American and European practice is therefore unique in the current literature. Other strengths include the comprehensive case ascertainment and collection of procedural covariates key to clinical decision-making. Data collected by the registries are broadly consistent and the majority of relevant clinical details can be reliably determined. We believe that observations and discussion of practice influences are germane beyond the areas studied.

Our study has some weaknesses. The Mayo Clinic as a major academic centre may not necessarily directly reflect US practice and includes patients from outside the local region. As a relatively smaller community of operators, practice may also change at a more rapid rate. In addition, a small fraction of total US practice is represented, with comparatively greater proportions of UK, Canadian (both approximately 10\%), and Belgian (close to $100 \%$ ) clinical activity represented. We accept that this is therefore not a comprehensive survey; sample proportions from each country vary and that other practice patterns are possible, even within the countries studied.

We used registry data to obtain a representation of actual clinical practice and rely on surrogates such as stent dimensions. Furthermore, each data set is not centrally audited, thus we cannot exclude idiosyncrasies between data sets. Despite this, key variables were defined consistently, and determined from original lesion and patient records.

Our study has an observational, descriptive design. To place our findings in context, we drew on previous literature and identified key external pressures on clinical practice. Because of this and the complex nature of the trends identified, much of our results and discussion are therefore qualitative. As with all observational studies, we cannot be sure that all relevant variables are accounted for within the adjusted analysis and it is not possible to demonstrate causal link between a given event and change in practice. Segmented timeseries analysis can be used in ecological studies to identify temporal changes in relation to external events; however, this approach would have been too simplistic in this case.

\section{Conclusion}

International adoption and use of DES showed wide variation in this study of PCI practice in four countries. Reductions in DES use were observed during 2006, but the timing and nature of this reduction also varied geographically. A consensus therefore does not exist for the optimum application of DES in clinical practice, although influences on stent choice in the "real world" are multifactorial. These data are a reminder of the gap that often exists between the goal of evidence-base medicine and actual clinical practice.

\section{Acknowledgements}

We thank the clinical and administrative staff who participate in data collection. Participating sites were: Alberta-Foothills Medical Centre (Calgary), Royal Alexandra Hospital (Edmonton), University of Alberta Hospital (Edmonton); Belgium-UZ Gent (Gent), UZ Gasthuisberg (Leuven), UZ Antwerpen (Edegem), OLV-Ziekenhuis (Aalst), ZOL Campus Sint-Jan (Genk), Imelda Ziekenhuis (Bonheiden), Virga Jesse (Hasselt), ASZ (Aalst), Middelheim Ziekenhuis (Antwerpen), AZ St Jan (Brugge), Ziekenhuis Maria Middelares (Gent), AZ Groeninge (Kortrijk), AZ Damiaan Campus St Jozef (Oostende), Clinique Univ St Luc (Bruxelles), Hôpital Erasme (Bruxelles), VUB Akademisch Ziekenhuis (Bruxelles); BHCClinique St-Jean et SARE (Bruxelles), Hôpital Univ Brugmann (Bruxelles), Clinique Sainte-Elisabeth (Bruxelles), Hôpital Univ St Pierre (Bruxelles), HIS Site Bracops (Bruxelles), CHU de Liège Sart Tilman (Liège), Clinique Univ de Mont-Godinne (Yvoir), Hôpital Civil de Charleroi (Charleroi), CHU Tivoli (La Louvière), CHR de la Citadelle (Liège), Hôpital St Joseph (Gilly), Hôpital de Jolimont (La Louvière), Clinique Saint-Camille (Namur), Clinique St Joseph (Arlon), Hôpital St Luc (Bouge), Centre Hospitalier Hutois (Huy), Scotland-Aberdeen Royal Infirmary, 
Glasgow Royal Infirmary, Golden Jubilee National Hospital (Clydebank), Hairmyers (East Kilbryde), Royal Infirmary (Edinburgh), Western Infirmary (Glasgow), Western General Hospital (Edinburgh), and Mayo Clinic (Rochester, MN). We wish to acknowledge the support and contribution of the Scottish Coronary Revascularisation Registry committee: Mrs Rachel Slack, Drs Hany Eteiba, Andrew D Flapan, Kevin P Jennings, Robin J Northcote, Alastair CH Pell, Ian R Starkey, and John Irving.

\section{Disclosures}

Dr Austin and Prof JP Pell have received research funding from Boston Scientific. Dr Oldroyd has received speaker and consultancy fees from Boston Scientific, Medtronic and Cordis. No other conflicts of interest.

\section{References}

1. Morice MC, Serruys PW, Sousa JE, et al. A randomized comparison of a sirolimus-eluting stent with a standard stent for coronary revascularization. N Engl J Med 2002;346:1773-80.

2. Moses JW, Leon MB, Popma JJ, et al. Sirolimus-eluting stents versus standard stents in patients with stenosis in a native coronary artery. N Engl J Med 2003;349:1315-23.

3. Grube E, Silber S, Hauptmann KE, et al. TAXUS I: six- and twelve-month results from a randomized, double-blind trial on a slow-release paclitaxel-eluting stent for de novo coronary lesions. Circulation 2003;107:38-42.

4. Stone GW, Ellis SG, Cox DA, et al. A polymer-based, paclitaxel-eluting stent in patients with coronary artery disease. N Engl J Med 2004;350:221-31.

5. Thomas M. Are drug eluting stents really worth the money? Heart 2006;92:5-7.

6. Bagust $A$, Grayson AD, Palmer ND, et al. Cost effectiveness of drug eluting coronary artery stenting in a UK setting: cost-utility study. Heart 2006;92:68-74.

7. Ryan J, Cohen DJ. Are drug-eluting stents cost-effective?: it depends on whom you ask. Circulation 2006;1 14:1736-44.

8. Eisenberg MJ. Drug-eluting stents: the price is not right. Circulation 2006; 1 14:1745-54.

9. National Institute for Health and Clinical Excellence (NICE). Guidance on the use of coronary stents. Available at: http:// www.nice.org.uk/page.aspx?o=TA071 guidance. Last accessed 3 December 2007.

10. National Institute for Health and Clinical Excellence (NICE). Drug-eluting stents for the treatment of coronary heart disease. Available at: http://www.nice.org.uk/guidance/index.jsp?action= download\&o=39068. Last accessed 10 March 2008.

11. Working Group on Drug Eluting Stents. Report on initial utilization strategy: final report and recommendations. Toronto: Cardiac Care Network of Ontario, December 2002:15. Available at http://www. ccn.on.ca/pdfs\%5CFinalDrugElutingMaster2_Dec2002.pdf. Last accessed 20 May 2008.

12. Neyt $M$, Van Brabant $H$, Devriese $S$, et al. Drug-eluting stents in Belgium: Health Technology Assessment. Bruxelles: Belgian Health Care Knowledge Centre (KCE); 2007. KCE reports 66C (D/2007/10.273/49).

13. Camenzind E, Steg PG, Wijns W. Stent thrombosis late after implantation of first-generation drug-eluting stents. A cause for concern. Circulation 2007;115:1440-55.
14. Nordmann AJ, Briel M, Bucher HC. Mortality in randomized controlled trials comparing drug-eluting vs. bare metal stents in coronary artery disease: a meta-analysis. Eur Heart J 2006;27: 2784-814.

15. Pfisterer M, Brunner-La Rocca HP, Buser PT, et al. Late clinical events after clopidogrel discontinuation may limit the benefit of drug-eluting stents: an observational study of drug-eluting versus bare-metal stents. J Am Coll Cardiol 2006;48:2584-91.

16. Lagerqvist B, James SK, Stenestrand U, et al. Long-term outcomes with drug-eluting stents versus bare-metal stents in Sweden. N Engl J Med 2007;356:1009-19.

17. Daemen J, Wenaweser P, Tsuchida K, et al. Early and late coronary stent thrombosis of sirolimus-eluting and paclitaxel-eluting stents in routine clinical practice: data from a large two-institutional cohort study. Lancet 2007;369:667-78.

18. Rao SV, Shaw RE, Brindis RG, et al. Patterns and outcomes of drugeluting coronary stent use in clinical practice. Am Heart J 2006;152: 321-6.

19. Austin D, Oldroyd KG, McConnachie A, et al. Hospital and operator variations in drug-eluting stent use: a multi-level analysis of 5967 consecutive patients in Scotland. J Public Health 2008;30: 186-93.

20. Grilli R, Guastaroba P, Taroni F. Effect of hospital ownership status and payment structure on the adoption and use of drug-eluting stents for percutaneous coronary interventions. CMAJ 2007;176: 185-90.

21. Bowman AW, Azzalini A. Applied smoothing techniques for data analysis: the kernel Approach with S-Plus illustrations. Oxford: Oxford University Press; 1997.

22. R Development Core Team. R: a language and environment for statistical computing. Vienna: R-Foundation for Statistical Computing; 2006. Available at: http://www.r-project.org. Last accessed 17th June 2008.

23. US Food and Drug Administration. CYPHER Sirolimus-eluting Coronary Stent on RAPTOR Over-the-Wire Delivery System or RAPTORRAIL Rapid Exchange Delivery System-P020026. Available at: http://www.fda.gov/cdrh/pdf2/P020026.html. Last accessed January 8, 2008.

24. US Food and Drug Administration. TAXUS Express 2 PaclitaxelEluting Coronary Stent System (Monorail and Over-the-Wire)P030025. Available at: http://www.fda.gov/cdrh/pdf3/P030025. html. Last accessed January 8, 2008.

25. Artis $L$, Burkhart $T$, Johnson T, et al. Physician factors as an indicator of technological device adoption. J Med Syst 2006;30:177-86.

26. Mark DB. Interpreting the music of drug-eluting stents: halcyon song or albatross dirge? J Am Coll Cardiol 2008;51:1854-6.

27. Packer C, Simpson S, Stevens A, on behalf of EuroScan: the European Information Network on New and Changing Health Technologies. International diffusion of new health technologies: a ten-country analysis of six health technologies. Int J Technol Assess 2006;22 419-28.

28. Shrive FM, Manns BJ, Galbraith PD, et al. for The APPROACH Investigators. Economic evaluation of sirolimus-eluting stents. CMAJ 2005; 172:345-51.

29. Brophy JM, Erickson $\sqcup$. Cost-effectiveness of drug-eluting coronary stents in Quebec, Canada. Int J Technol Assess 2005;21:326-33.

30. Bowen J, Hopkins R, He Y, et al. Systematic review and costeffectiveness analysis of drug eluting stents compared to bare metal stents for percutaneous coronary interventions in Ontario: interim report. Report no. HTA002-0512, prepared for the Ontario Ministry of Health and Long-term Care. Hamilton, ON, Canada: Program for Assessment of Technology in Health, McMaster University, December 
2005:170. Available at: http://www.path-hta.ca/DESreport.pdf. Last accessed 20 May 2008.

31. Holmes DR, Moses JW, Schofer J, et al. Cause of death with bare metal and sirolimus eluting stents. Eur Heart J 2006;27:2815-22.

32. Stone GW, Moses JW, Ellis SG, et al. Safety and efficacy of sirolimusand paclitaxel-eluting coronary stents. N Engl J Med 2007;356: 998-1008.

33. Kastrati A, Mehilli J, Pache J, et al. Analysis of 14 trials comparing sirolimus-eluting stents with bare-metal stents. N Engl J Med 2007; 356:1030-9.

34. Spaulding C, Daemen J, Boersma E, et al. A pooled analysis of data comparing sirolimus-eluting stents with bare-metal stents. N Engl J Med 2007;356:989-97.

35. Stettler C, Wandel S, Allemann S, et al. Outcomes associated with drug-eluting and bare-metal stents: a collaborative network metaanalysis. Lancet 2007;370:937-48.

36. Tu JV, Bowen J, Chiu M, et al. Effectiveness and safety of drug-eluting stents in Ontario. N Engl J Med 2007;357:1393-402.

37. Pasceri V, Patti G, Speciale G, et al. Meta-analysis of clinical trials on use of drug-eluting stents for treatment of acute myocardial infarction. Am Heart J 2007;153:749-54.
38. Marroquin OC, Selzer F, Mulukutla SR, et al. A comparison of baremetal and drug-eluting stents for off-label indications. N Engl J Med 2008;358:342-52.

39. Applegate RJ, Sacrinty MT, Kutcher MA, et al. "Off-label" stent therapy: 2-year comparison of drug-eluting versus bare-metal stents. J Am Coll Cardiol 2008;51:607-14.

40. Austin D, Oldroyd KG, McConnachie A, et al. Drug-eluting stents versus bare-metal stents for off-label indications: a propensity scorematched outcome study. Circ Cardiovasc Intervent 2008;1:45-52.

41. McFadden EP, Stabile E, Regar E, et al. Late thrombosis in drugeluting coronary stents after discontinuation of antiplatelet therapy Lancet 2004;364:1519-21.

42. Virmani R, Guagliumi G, Farb A, et al. Localized hypersensitivity and late coronary thrombosis secondary to a sirolimus-eluting stent: should we be cautious? Circulation 2004;109:701-5.

43. lakovou I, Schmidt T, Bonizzoni E, et al. Incidence, predictors, and outcome of thrombosis after successful implantation of drug-eluting stents. JAMA 2005;293:2126-30.

44. Eisenstein EL, Anstrom KJ, Kong DF, et al. Clopidogrel use and longterm clinical outcomes after drug-eluting stent implantation. JAMA 2006;297:159-68 